\title{
Innovation clusters in technological systems: a network analysis of 15 OECD countries for the middle ' $90 \mathrm{~s}^{*}$
}

\author{
Sandro Montresor $^{\dagger} \quad$ Giuseppe Vittucci Marzetti ${ }^{\ddagger}$
}

December 17, 2008

\begin{abstract}
The paper aims at investigating how innovations cluster in different technological systems (TSs) when their "techno-economic", rather than "territorial" space is considered. Innovation clusters of economic sectors are identified by applying network analysis to the intersectoral R\&D flows matrices of 15 OECD countries in the middle '90s. Different clusterization models are first tested in order to detect the way sectors group on the basis of the embodied R\&D flows they exchange. Actual clusters are then mapped in the different TSs by looking for intersectoral relationships which can be qualified to constitute "reduced-TSs" (ReTSs). In all the 15 TSs investigated the techno-economic space appears organized in hierarchies, along which its constitutive sectors group into clusters with different density and composition. Once ReTSs are looked for, the 15 TSs display highly heterogeneous structures, but with some interesting similarity on the basis of which different clusters of TSs can be identified in turn.
\end{abstract}

Keywords Innovation clusters; Technological systems; R\&D expenditure; Embodied innovation flows

JEL Classification: O33; O38; O39

${ }^{*}$ Acknowledgments: We are extremely grateful to Bo Carlsson and Fulvio Castellacci for their suggestions on a previous version of this paper, and to the participants to the 2007 DRUID Summer Conference for their comments. Usual caveats apply.

${ }^{\dagger}$ Department of Economics, Univ. of Bologna, Italy. E-mail: sandro.montresor@unibo.it

${ }^{\ddagger}$ Department of Economics, Univ. of Bologna, Italy. E-mail: gvittucci@yahoo.it 


\section{Introduction}

Interactions and knowledge exchanges, both among firms and other institutions (such as, for example, universities and research labs), are at the heart of the innovation process. This is one of the starting points of the neoschumpeterian and evolutionary analysis of technological change, in which the role of interdependence has been founded on such notions as "produceruser relationships" (von Hippel, 1976), "learning-by-interacting" (Lundvall, 1992), "knowledge division" (Loasby, 2000), "community of practice" (Lave and Wenger, 1991), just to mention a few. ${ }^{1}$

Interactions have been recently brought to the front of the debate in innovation studies, also and above all because of their role in explaining such important phenomena as "innovation clusters" and "systems of innovations". Although developed quite independently, these two concepts have recently come to overlap substantially. However, this overlapping has mainly concerned the clustering of innovations in the territorial space, such as for the idea of regional system of innovation (e.g. Cooke et al., 1997). Conversely, it has gone somehow neglected with respect to another important kind of clustering, in what can be called the techno-economic space, in brief:

not [a] topographical, geographical space but [...] an abstract economic space of supply and demand of different goods (as represented by input-output matrices) and [a] technical space (as represented by the techno-functional classification of patents) (DeBresson, 1996d, p.151). ${ }^{2}$

In this paper we intend to fill this gap by showing that the nature and the number of innovation clusters one can identify in the techno-economic space can be used to analyze the structure of their hosting technological systems (TSs). In particular, as we will do in the paper, by investigating the patterns of innovation clustering in different TSs, and by looking for techno-economic clusters which can be qualified as "reduced TSs" (ReTSs) for them.

This kind of analysis is carried out with respect to 15 OECD countries for the middle '90s. More precisely, by drawing on, but also expanding substantially, the methodology of previous works on the issue (e.g. Leoncini

\footnotetext{
${ }^{1}$ The innovation role of interdependence has been recognized also by standard neoclassical accounts, in which it has been founded on different concepts such as those of "externalities" and "spillovers". However, these concepts reflect a methodological individualism which somehow clashes with the idea of interdependence itself. As Christian DeBresson observed: "Only if one assumes totally free individual economic agents with no stable external relationships, joint interests, joint constraints, or commitments can the concept of externality make sense." (DeBresson, 1996a, p.76).

${ }^{2}$ To be sure, for both theoretical and practical reasons (on which see Leoncini and Montresor, 2000b), in this paper the "technical" side of the techno-economic space will be rather represented by the sectoral classification of $R \& D$ expenditure.
} 
and Montresor, 2003c), their TSs are compared through specific network analysis techniques applied to qualified matrices of intersectoral innovation flows.

The structure of the paper is the following. Section 2 explores the idea of innovation clustering in the techno-economic space and its relationship with the notion of TS. Section 3 details the network analysis techniques used in the application and emphasizes important differences with respect to previous applications. Section 4 illustrates the main results of the comparative application. Section 5 concludes.

\section{Innovation clusters in technological systems}

\subsection{Innovation clusters in the techno-economic space}

The spatial clustering of innovations has been recognized as a central feature of advanced national economies (e.g. Porter, 2000), and thus investigated by several theoretical positions. Relative less attention has been instead attracted by another kind of interdependence, which manifests itself through the clustering of innovation activities in the techno-economic space. This can be meant as the (abstract) reference space originated by the interaction of two dimensions: on the one hand, the meso-economic mechanisms of innovation inducement represented by the intersectoral relationships of an economic system; on the other hand, the meso-technological constraints and opportunities determined by the sectoral distribution of the innovative efforts and outcomes of an innovation system (DeBresson, 1996d; Leoncini and Montresor, 2003a). Such a space is thus the "bi-dimensional" one which emerges by mapping the innovation process at the intersectoral level.

Innovation clustering in this techno-economic space has a manifold theoretical explanation. On the one hand, it is grounded on the idea that input-output coefficients, and the related backward and forward linkages, represent the inverse of an economic kind of distance between firms (of different sectors), which crucially affects their "learning-by-interacting" and the entailed knowledge networks: the greater an intersectoral coefficient is, the closer the related sectors are in economic terms, the more the relative firms are able to engage in network kinds of relationships which increase their innovative opportunities (Lundvall, 1992; DeBresson, 1996c). On the other hand, "techno-economic clustering" relies on the idea that input-output matrices map intersectoral flows of goods (both intermediate and capital) and services which shape the intersectoral diffusion of innovation: both directly, that is by channeling embodied innovation flows, and indirectly, that is by driving disembodied technology flows (Marengo and Sterlacchini, 1990).

Of course, those forces which drive the spatial and the techno-economic clustering of innovations can be at work simultaneously and possibly reinforce each other (DeBresson, 1996b). However, two firms operating in the 
same sector are economically close even if they are geographically dispersed. Therefore, spatial clustering does not represent a necessary pre-requisite for techno-economic clustering, and the relative techno-economic space can be deemed territorially neutral.

For this reason, the present paper will focus on the techno-economic space identified by national input-output tables, once sectoral innovative efforts are distributed along them consistently. ${ }^{3}$

\subsection{The techno-economic relationships of a technological system}

The role of interactions for the innovative process, and that of institutions enabling them (Edquist and Johnson, 1997; Johnson, 1992), are crucial in the massive literature on the systems of innovations (Edquist and McKelvey, 2000).

Among the numerous system concepts which have been put forward, in this paper we will refer to a broad notion of technological system (Leoncini, 1998; Leoncini and Montresor, 2003b) which combines institutional elements with other elements for which the functional (i.e. sectoral) boundaries of an economy - that is the techno-economic space - are at least as important as the geographical ones - that is the territorial space. One of the distinguishing features of this notion is that the relationships occurring in the "technoeconomic space" are crucial in investigating the functioning of the TS subsystems and of the TS as a whole (Leoncini and Montresor, 2003c). In particular, the techno-economic relationships of this TS can be proxied with the R\&D flows circulating among its economic sectors being embodied in their vertically integrated relationships. And, given the way they are measured, these flows can actually be deemed techno-economic in nature and shaped by the constitutive sub-systems of the broad notion of TS we are referring to (Leoncini and Montresor, 2003a). ${ }^{4}$

As has been shown in a number of studies (e.g. Leoncini et al., 1996;

\footnotetext{
${ }^{3}$ Although the techno-economic space spans across the boundaries of one country, referring to national input-output tables can be motivated on the basis of two arguments. First, super-national input-output matrices are not yet available to carry out systematic empirical analysis, while measuring international innovation relationships embodied in intersectoral import flows suffers from important methodological problems (Leoncini and Montresor, 2003a). Second, even in the globalisation era, important differences emerge among countries in the way the innovative process takes place and is organized at various levels of analysis.

${ }^{4} \mathrm{R} \& \mathrm{D}$ flows embodied in intersectoral production flows reflect, by definition, the functioning of both the innovative sub-system (proxied by R\&D expenditure) and the production sub-system (proxied by input-output tables) of a TS. Furthermore, the resort to the notion of vertically integrated sectors allows the same flows to retain also the market sub-system through the role of final demand. As has been argued elsewhere (Leoncini and Montresor, 2005), the map can be refined by considering, still in an input-output framework, the role of the foreign market and of the institutional set-up.
} 
Leoncini and Montresor, 2000b, 2001, 2005; Chang and Shih, 2005), the TSs of different countries, both at the macro and the sectoral level, can be compared by applying specific network analysis techniques to these techno-economic flows. In the present paper we argue that, with some important additions and specifications, the same methodology can be used also in investigating how innovations cluster in the techno-economic space of different TSs. To these methodological specifications we turn in the next section.

\section{Intersectoral innovation flows and network analysis: "some new wine in an old bottle"}

\subsection{Direct and indirect innovation flows}

Drawing on Leoncini and Montresor (2003c), the constitutive relationships of the techno-economic space of a TS can be mapped by building up a $(n \times n)$ matrix $\mathbf{R}$ defined as:

$$
\mathbf{R}=\hat{\mathbf{r}} \hat{\mathbf{q}}^{-1}(\mathbf{I}-\mathbf{A})^{-1} \hat{\mathbf{y}}
$$

where $\hat{\mathbf{r}}, \hat{\mathbf{q}}$, and $\hat{\mathbf{y}}$ are the sectoral diagonal vectors of, respectively, $R \& D$ expenditures, gross production and final demand, and $(\mathbf{I}-\mathbf{A})^{-1}$ is the Leontief inverse based on the domestic input-output coefficients matrix $(\mathbf{A})$.

With respect to previous applications, the use of the $\mathbf{R}$ matrix in detecting techno-economic clusters now requires us to distinguish and consider both direct and indirect intersectoral $\mathrm{R} \& \mathrm{D}$ flows. This is necessary as the intersectoral innovation diffusion process represented by $\mathbf{R}$, although assuming sectoral intermediation in production, does not allow for sectoral intermediation in innovation. In a "stylized" TS made up of three economic sectors namely, metal products (sector $i$ ), non-electrical machinery (sector $k$ ) and automobiles (sector $j$ ) $-r_{i j}$ measures the innovation made by the metal products sector (sector $i$ ) which the automobile sector (sector $j$ ) acquires from it: both directly - that is embodied in the instruments it acquires from the metal products sector itself (sector $i$ ) - and indirectly - that is embodied in the instruments (still produced by sector $i$ ) used to produce those machines the automobile sector (sector $j$ ) gets from the non-electrical machinery one (sector $k$ ). However, although "intermediated" by the production of the machinery sector (i.e. by sector $k$ ), the innovation the automobile sector (sector $j$ ) receives via $r_{i j}$ is produced by the metal sector (sector $i$ ) only: that is, $r_{i j}$ does not admit that the machinery sector (sector $k$ ) could in turn innovate the metal products (sector $i$ ) it uses to produce those machines which are then bought by the automobile sector (sector $j$ ).

Therefore, the analysis of the total techno-economic flows occurring between two generic sectors $i$ and $j$ of $\mathbf{R}$ requires us to consider two kinds of flows. First, we should consider the innovation generated by $i$ and transferred, 
through direct and direct "production flows", to $j$, that is $r_{i j}$. Second, we have also to take into account those "intermediate" sectors $k$ s which receive embodied R\&D by $i$ and transfer their embodied R\&D to $j$, still through both direct and indirect production flows.

Once direct and indirect innovation flows have been disentangled, the kind of clusterization they entail can be investigated by applying two network analysis techniques which are usually adopted in studying grouping phenomena in social sciences. As we will show, both have an interesting interpretative meaning with respect to the present issue.

\subsection{Network analysis and clusterization patterns in technological systems}

Before identifying the actual number and nature of groups in a certain network, by means of Social Network Analysis we can investigate which model of clusterization better fits the relationships - technically called "arcs" - which are observed among its components - "vertices" or "nodes" - regardless of the prospective number of groups.

Drawing on the hypotheses and the testing procedures about patterns of affective relations coming from social psychology and generally known as balance theory, a set of models have been formalized in order to identify the structure that networks reveal in terms of relationships within and between groups. ${ }^{5}$ In their economic applications, these balance-theoretic models are possibly less popular than others. In particular, than those which, by means of the so called "generalized blockmodeling" (Doreian et al., 2005), look for a "core-periphery" structure often envisaged also in (territorial) systems of innovation. However, the analysis of "triads" - groups of three vertices and the lines between them - on which balance-theoretic models are based, is less demanding of hypotheses than generalized blockmodeling, instead based on the analysis of "contingency matrices" - matrices of 1 s and 0s denoting, respectively, the presence and the absence of a relationship between couples of vertices. What is more, balance-theoretic models allow us to search in TSs a different set of configurations for its techno-economic activities. Indeed, as we will argue, the main models of this kind have a quite interesting equivalent in the way a TS is organized when the techno-economic relationships among its sectors are considered.

Following Holland and Leinhardt (1970, 1971, 1975), we can refer to two groups of models. The first group investigates how well the hypothesis of "cohesive groups" with no "external" relationships fits the actual data. In

\footnotetext{
${ }^{5}$ In brief, the basic idea is that a person feels uncomfortable if there are "negative" relations with other persons belonging to his group (hostility, disliking or disagreement on some topics). Such feelings make disorganized networks balance into cohesive groups among which either no or hierarchical relationships establish. For an overview of these balance-theoretic models see Wasserman and Faust (1994, Ch.6).
} 
particular, two models can be tested.

(i) Balanced model. Observed networks are confronted with a hypothetical one made up of two large, very dense clusters, among which there are no ties. In formal terms, the candidate network structure is made up of no more than two "cliques", where a clique is a maximal complete subnetwork containing three vertices or more.

(ii) Clusterability model. The hypothesis is tested that actual networks are made up of a certain number $n$ of clusters $(n>2)$, still with very dense internal relationships and no external relationships. Formally, the model relaxes the assumption of two cliques of the balanced one, and allows networks to consist of more cliques.

The second group of models tests the hypothesis that cohesive groups can emerge in a network also by developing relationships among them, namely of hierarchical nature. Unlike within-cluster relationships, among-clusters ones are in fact assumed to be "asymmetric" - technically, the connecting lines have one direction only. Accordingly, they can reveal a "superiority" of higher ranked clusters with respect to lower ranked clusters. More precisely, three models of this kind can be tested:

(iii) Ranked clusters model. The model-network is assumed composed of a number of clusters, which are ranked in such a way that each vertex in a lower ranked cluster is connected in an asymmetric way with each one of the vertices in a higher cluster. Given that higher ranked clusters' vertices reach directly each of the vertices of all the lower ranked ones, in a sort of cascade, the kind of ranking this model assumes is thus quite strict.

(iv) Transitivity model. As in the previous model, the hypothesis is that network's clusters develop a hierarchy by means of asymmetric dyads couple of vertices and their connecting tie - among them. This time, however, the inherent ranking is admitted to be looser. Higher ranked clusters are in fact retained to be so even in the absence of direct ties toward the vertices of lower ranked ones, providing indirect ties - that is passing through intermediate ranked clusters - can be traced with respect to them. In formal terms, the only requirement to identify relations among clusters of different ranks is for them to be at least transitive.

(v) Hierarchical $\bar{M}$-clusters model. Looser ties are assumed and tested not only among clusters - as in the previous model - but also within them. Clusters are in fact admitted to be made also by asymmetric dyads, providing they still allow cyclic relationships to be identified for them which make their rank recognizable. 
As a "null hypothesis" with respect to the previous five models, a sixth one can be tested:

(vi) No balance-theoretic model. The way in which vertices are linked together does not fit any balance-theoretic model and it is therefore not possible to cluster or rank the actual vertices and arcs of a network.

As we said, once a TS is thought as a network of sectors linked by technoeconomic relationships - i.e. intersectoral embodied R\&D flows - these six models can be read as six different ways in which a TS can be organized. A "balanced-model", for example, would suggest a dichotomic TS, marked by the presence of two independent sub-systems of innovation, resembling what has been identified by a more qualitative and institutional oriented literature (e.g. Malerba, 1993). A TS organized according to the "clusterability model" would instead suggest the co-existence of several unrelated "technological trajectories" (Leoncini and Montresor, 2000a). The "ranked clusters", the "transitivity" and the "hierarchical $\bar{M}$-clusters" models are suggestive of "complex" (Potts, 2000) TSs, in which subsystems of different importance (i.e. rank) can be identified and organized into progressively less "complete" hierarchies. Finally, a TS network fitted by a no balance-theoretic model would signal an "atomistic" TS, whose constituent sectors do not further organize into sub-systems.

Once the actual clusterization pattern of a TS has been identified among these six, and we should stress endogenously, actual clusters can also be detected by assuming an adequate hypothesis about the way relationships occur within them. A crucial issue we will address in the next section.

\subsection{Symmetric Acyclic Decomposition (SAD) analysis and "Reduced Technological Systems" (ReTS)}

The working hypothesis on the basis of which we identify clusters in TSs is that of "strong components" (SC), obtained by applying a weak version of the Symmetric-Acyclic Decomposition (SAD) method (Doreian et al., 2000). In intuitive terms, SCs can be defined as maximal sub-networks of nodes (here sectors) among which the connecting arcs (here techno-economic flows) determine a cyclical relationship, so that a hierarchy cannot be established among them. ${ }^{6}$ While a SC is a cyclic (sub)network by definition, vertices

\footnotetext{
${ }^{6}$ The $S A D$ method is grounded on Davis and Leinhardt"s (1972) idea of ranked clusters models. In formal terms, given a directed graph $G=(V, E)$, that is, a set of vertices (or nodes or points) $(V)$ and a set of ordered pairs of these vertices specifying their relations $(E)$, a strong component of $G$ can be formally defined as the maximal subset of vertices $P \subset G$ such that there is a directed path within $P$ from $x$ to $y$ for each pair $\{x, y\} \in P$. A path from $x_{1}$ to $x_{k}$ is a graph $M=(Z, F)$ of the form:

$$
Z=\left\{x_{1}, x_{2}, \ldots x_{k}\right\} \quad F=\left\{x_{1} x_{2}, x_{2} x_{3}, \ldots x_{k-1} x_{k}\right\}
$$

where $x_{1}, x_{2}, \ldots x_{k}$ are all distinct (Diestel, 2005).
} 
which are not a part of a strong component cannot belong to a cycle. Thus, if we "shrink" the SCs of a network, and make them of one node each, the network becomes ipso facto acyclic, that is, strongly hierarchical: its vertices and SCs can thus be ranked accordingly.

The rationale of this choice is given by the search of clusters which have a truly system nature, and can thus be qualified as "reduced-form" systems: in our case, "Reduced Technological Systems" (ReTSs). ${ }^{7}$ It seems to us that the concept of SC actually contains the rationale to operationalize quantitatively the idea of ReTSs. Indeed, what attributes to a cluster of sectors an actual system nature, and makes of it a ReTS within a TS, is the presence of heterarchical relationships among its constitutive elements: a condition that the cyclical nature of the SC relationships guarantees by definition. Accordingly, a SC describes a cluster as systemic, given that its functioning is distributed among its components (sectors), rather than polarized and dependent on some of them more than on others.

To identify a ReTS with a SC is for sure a stringent criterion, which excludes "simpler" compositions of elementary structures addressed by other cluster techniques, such as "technological complexes" and "simple agglomerations" (DeBresson et al., 1996). On the other hand, a SC is less stringently defined than a "clique", where all the participating sectors supply each other with their techno-economic outputs (DeBresson et al., 1996). In other words, a SC which is also a clique qualifies a ReTS as systemic to the maximum extent. Therefore, comparing different TSs on the basis of their innovative cliques is also important.

\section{An empirical application to 15 OECD technological systems for the middle' 90 s}

As in other previous works, network analysis is here applied to an appropriate transformation of $\mathbf{R}(n \times n)$, $\mathbf{C}(n \times n)$ : a matrix which neutralizes scale differences across different TSs and neglects intrasectoral innovation flows by referring to normalized intersectoral innovative acquisitions (Leoncini and Montresor, 2000b). More precisely, the $\mathbf{C}$ matrices are here built up by matching two OECD datasets: the "new" OECD Input-Output Database (2005), containing consistent input-output tables at current prices for 20

\footnotetext{
${ }^{7}$ The term "reduced-form" is here borrowed from the modeling community and refers to a "respecified system of endogenous relationships that permit one to grasp system essential, identify their key function, or to derive practical findings" (OECD, 2001, p.14). The importance of "reduced-systems" for innovation systems of national scale has been recently suggested by the well-known OECD program on the issue (OECD, 1999, 2001), which defines them, in inner techno-economic terms, as: "the most essential and functional system elements [which] stimulate the emergence of specific kinds of innovation in various segments of a national economy" (OECD, 2001, p.8, emphasis ours). The kind of space reduced-systems refer to is thus in fact a techno-economic, rather than a territorial one.
} 
countries and 41 sectors with respect to the middle '90s, and the $O E C D A N$ BERD (Analytical Business Enterprise Research and Development) Database (2005), on which data on sectoral R\&D expenditure have been drawn for the correspondent countries and years. The numerous blanks in the series of the latter dataset have forced us to limit our empirical application to 15 countries (Appendix A) and 16 sectors only, out of which 15 are manufacturing (including constructions) and one a service sector (Appendix B).

Before presenting the results a methodological clarification is important. The countries of the dataset are quite different among them. Not only in terms of size and R\&D intensity, but also and above all when their national systems of innovations are compared. Although we are aware of these macroscopic differences, in the following we will try to show whether systematic differences and similarities emerge among them when the techno-economic space of their TS is explored in the same way: that is, by looking for and characterizing techno-economic clusters which can be deemed reduced-TSs.

\subsection{To start with: dichotomization and density}

As the majority of the network analysis techniques, also those we will use in the paper require us to work with dichotomic matrices: in our case, dichotomized $\mathbf{C}$ matrices, made up of 1 s and 0s according to a "greater-than" test of $c_{i j}$ with respect to a certain cut-off value, $t$. Given the sensitivity of the results to the threshold value $(t)$, its choice has to be carried out cautiously, especially in comparative exercises. Accordingly, in the following we stick to Leoncini and Montresor (2000b) and choose it on the basis of the density $\left(D_{t}\right)$ the TSs compared reveal for a large set of cut-off values.

Defined as the ratio between the actual number of cells of $\mathbf{C}\left(s_{C}\right)$ which are greater than $t$, and the maximum number of cells of the same matrix $(n \times(n-1)), D_{t}$ informs us about the role of $t$ in shaping the structure of the correspondent TS-network. ${ }^{8}$ Therefore, the TS-sensitivity to dichotomization can be explored by examining the density distribution $\left(\mathbf{d}_{\mathbf{t}}\right)$ a certain TS (i.e. its "mirrored" C) shows with respect to a suitable vector of cut-off values t. ${ }^{9}$ In the following, the density of the 15 TSs is compared with respect to a "super-vector" of cut-offs $\left(\mathbf{t}_{\mathbf{Z}}\right)$ whose $Z$ elements are obtained by ordering the cells of all the 15 matrices $\mathbf{C}(Z=(15 \times 16) \times 15=36000) \cdot{ }^{10}$

\footnotetext{
${ }^{8}$ The TS's arcs are in fact valued by the cells of $\mathbf{C}$ itself. In formal terms, $D_{t}=\frac{s_{C}}{n(n-1)}$ with $0 \leq D_{t} \leq 1$.

${ }^{9}$ In Leoncini and Montresor (2000b), for example, $\mathbf{t}$ is the ordered distribution of the cells of the correspondent matrix $\mathbf{C}$, so that the density of a certain TS is maximum (and equal to 1) and minimum (and equal to 0 ) when the cut-offs are, respectively, the minimum and the maximum of its constitutive techno-economic flows.

${ }^{10}$ In Leoncini and Montresor (2000b), instead, a reference $\mathbf{t}_{\mathbf{z}^{*}}$ is chosen (arbitrarily) out of the $z$ matrices $\mathbf{C}$ to be compared, and with respect to it the density of all the other $(z-1)$ TSs is then worked out. In the comparison, the density distribution of the reference country-TS $\left(\mathbf{d}_{\mathbf{t z}_{\mathbf{z}}}\right)$ turns out linear and the other TSs can be qualified as relatively more
} 
Unfortunately, for an as large set of cut-offs, very few general trends can be identified across the all 15 TSs. However, interesting insights can be obtained by grouping them according to the similarity of their density distribution. In this last respect, Figure 1 shows five groups of TSs whose density distributions are "non-linear", or at least not as linear as those of a sixth group, made up of Canada, Germany and the UK (Figure 1(a)). With respect to the $15 \mathrm{TSs}$ investigated, these three thus have an average degree of connectivity. However, they are also the most "homogeneous", as considering small rather than large techno-economic flows does not make them recovering or loosing many positions in the ranking according to the highest density.

In the other $12 \mathrm{TSs}$, instead, the size of the retained techno-economic flows affects their relative density with different patterns. The "upwarddownward concavity" path shared by France and Italy (Figure 1(b)), for example, shows that by retaining also very small and small techno-economic flows, respectively, France and Italy are in fact the least dense, while they turn into the most dense when large and very large flows only are retained. This is quite interesting and suggestive of a sort of dichotomy in the same TSs, which at least for Italy has been also documented by other sources (Malerba, 1993). The previous pattern is contrasted by the "downwardupward concavity" one shown by Australia and Japan (Figure 1(c)), which both have widespread intersectoral techno-economic linkages, although many of these are somewhat "secondary" and become null for large cut-offs (a similar path is revealed by Finland and Norway (Figure 1(d))).

Among the other groups, a special attention deserves that identified by three TSs that in the retained period have displayed quite remarkable innovative performances and distinguished for important transformations in the relative institutional set-up: Korea, Spain and the US (Figure 1(e)). ${ }^{11}$ Quite interestingly, if we except the post-socialist countries (i.e. Poland and the Czech Republic (Figure 1(f))), on which we will come back later, these are the only TSs of the 15 compared whose density distribution is above the bisector for a large range of $t$ values, though still relatively close to it.

\subsection{The choice of the cut-off value}

To pick up one cut-off only and carry out our analysis with respect to it is for sure arbitrary to a certain extent. However, by referring to the density distributions of Figure 1 we are able to both justify its choice and control

\footnotetext{
or less dense, depending on their distribution being, respectively, above or below it.

${ }^{11}$ On the "evolutionary" changes occurred in the Korean government research institutes see Yim and Kim (2005). On the initial, but remarkable, first steps of the Spanish system of innovation see European Commission (2006). On the recent shifts in the US funding of $\mathrm{R} \& \mathrm{D}$, toward important cuts in defense related spending, and major overlap in public and private research requirements, see Hill (2006).
} 


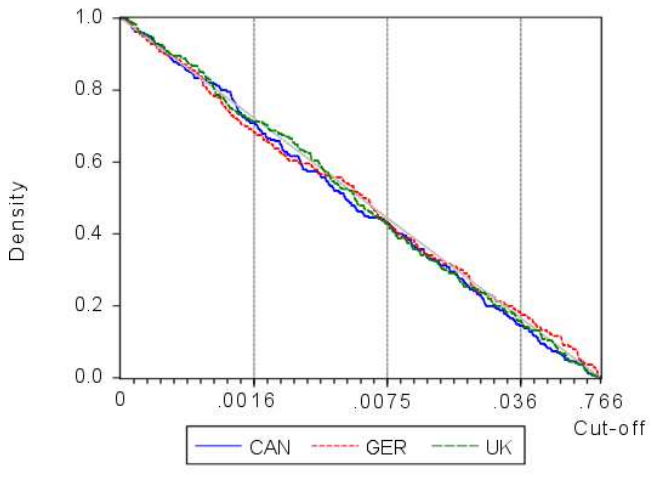

(a)

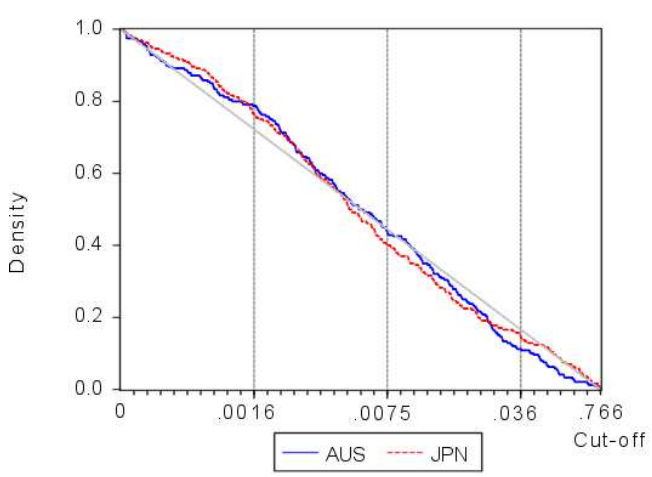

(c)

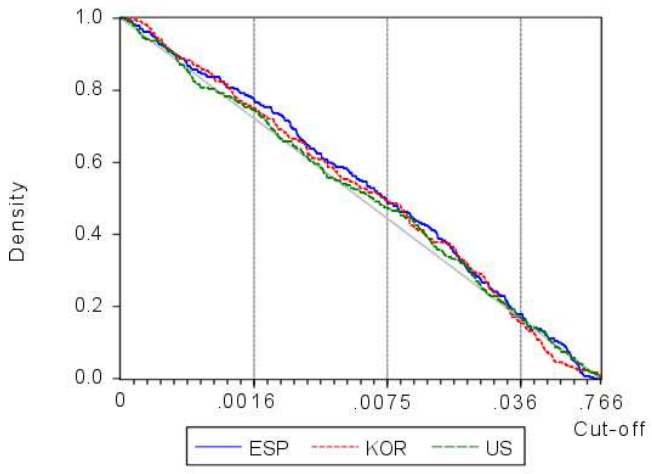

(e)

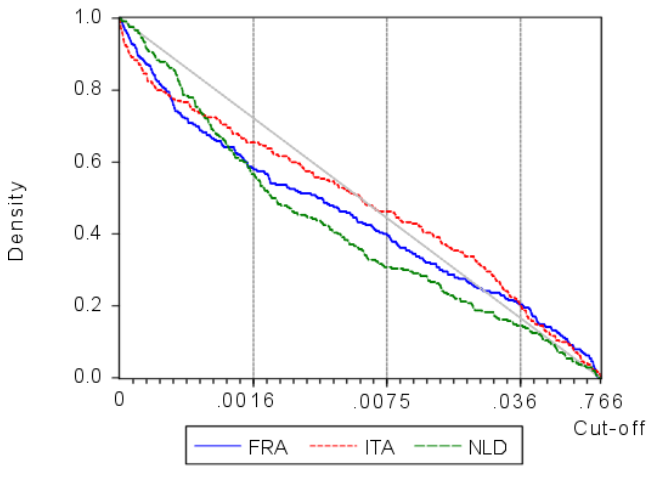

(b)

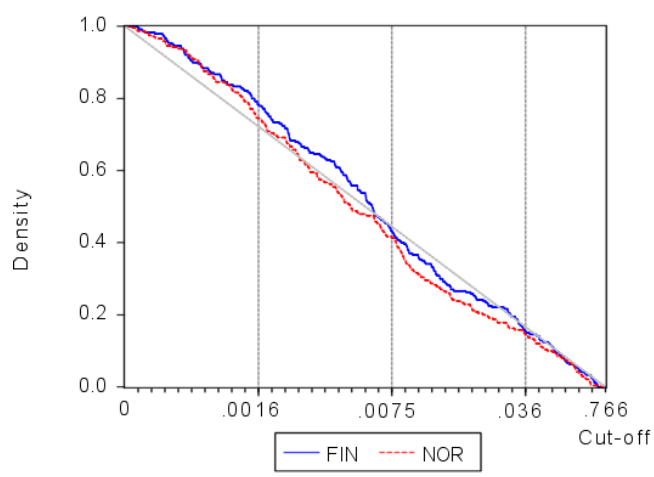

(d)

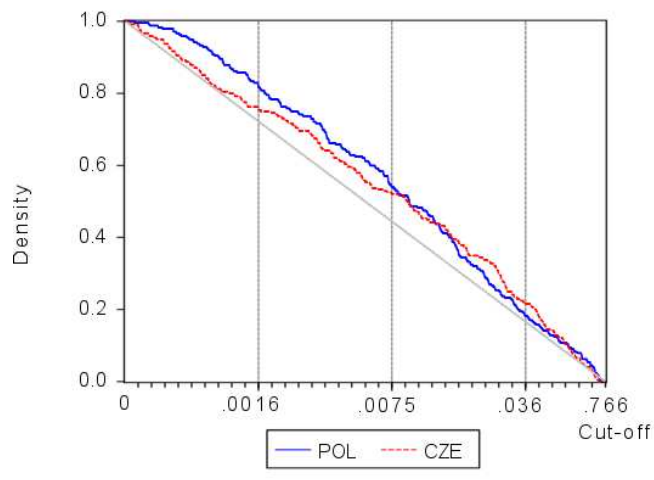

(f)

Figure 1: Density distribution graphs 
for the robustness of the results.

As for the first point, we have looked for that cut-off which most enables us to retain TS structures which are both significant in structure and not too dissimilar in density. Indeed, in this way we have tried to further neutralize scale effects and actually capture pure relational aspects. ${ }^{12}$

Following this calibration procedure, a reliable reference point for our analysis has emerged to be the cut-off value $t=.0111$. Indeed, for $t=.0111$ we have been able to detect the maximum degree of similarity which is possible to have far from the extremes, that is (see Table 1): (i) the density values of the 15 TSs fluctuate in a range of $.18(.463-.283)$, definitively a small one; (ii) the average difference among the densities of the 15 TSs is .02 , with a very low variance (.000184); (iii) three groups of TSs, accounting for $60 \%$ of the total ( 9 out of 15 ), can be identified for which densities are equal, or nearly equal (Italy and the US; Australia, Germany and Canada; Finland and the UK; France and Japan).

Although this appears to us a "satisfactory choice", it remains somehow arbitrary. The density based method we have used allows us to control for the robustness of the results obtained when intersectoral techno-economic flows larger than $1.11 \%$ of the total are considered only. In this last respect, we should clarify that our expectations are for non-robust results. In other words, given the density-distribution analysis carried out in Section 4.1, we expect that differences emerge with respect to the choosen cut-off when technoeconomic flows of different size are retained. In this sense, the sensitivity analysis we will carry out in Section 4.5 will try to check whether some of the results obtained for $t=.0111$ hold for other cut-off values too and, more in general, how they change when flows of a different size are considered.

\subsection{Technological systems and patterns of clusterization}

In order to assess which one of the six alternative structural models outlined in Section 3.2 better fits the networks of our 15 TSs, we have carried out a "triad census" on them. The results we got from it are quite incontrovertible (Table 2$) \cdot{ }^{13}$

At the outset, for all the considered TSs the $\chi^{2}$ statistics strongly reject

\footnotetext{
${ }^{12}$ By definition, the densities of the compared TSs are all exactly equal, to 1 and 0 respectively, only for the extreme cut-offs ( $\min$ and $\max$ ) of the threshold distribution. In the neighborhoods of these cut-offs, however, the TSs degenerate in meaningless structures, either too dense to be investigated (around the minimum cut-off), or too spare to have a techno-economic meaning (around the maximum). Therefore, the best one can do is to look heuristically for density similarities, possibly pairwise or across groups of distributions, by referring to an appropriate intermediate cut-off value.

${ }^{13}$ On the analysis of triads in Social Network Analysis see, for instance, Wasserman and Faust (1994, Ch.14). All the calculations were made using Pajek 1.09, a program package for analysis and visualization of large networks freely available for noncommercial use (Batagelj et al., 2005).
} 


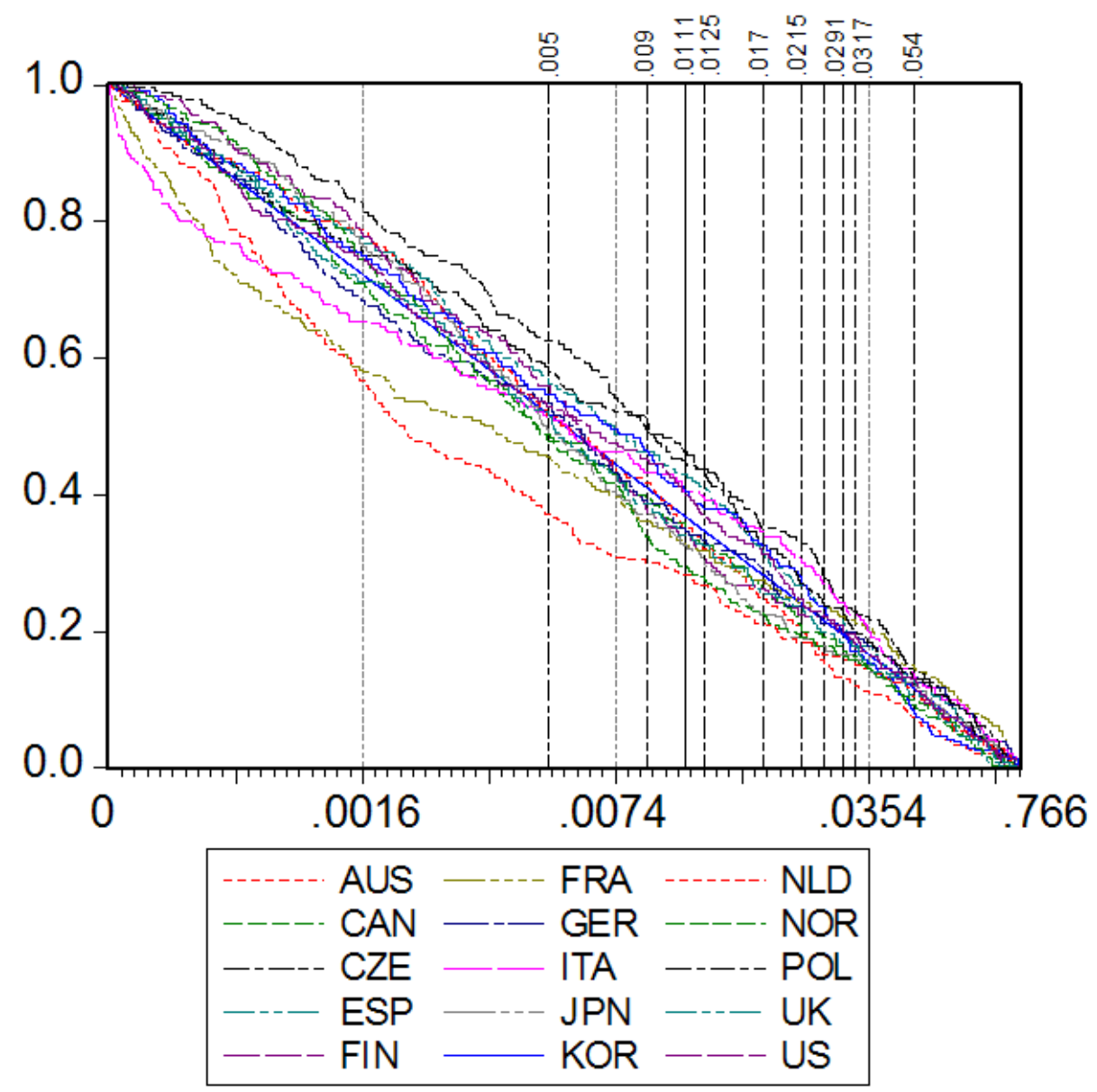

Figure 2: Density distribution graph with the chosen cut-off value

Table 1: Network densities $(t=.0111)$

\begin{tabular}{lc}
\hline Country & Network density \\
\hline Poland & .463 \\
Czech Republic & .450 \\
Spain & .429 \\
Korea & .408 \\
Italy, United States & .404 \\
Australia, Germany, Canada & .350 \\
Finland, United Kingdom & .342 \\
France, Japan & .325 \\
Norway & .296 \\
Netherlands & .283 \\
\hline
\end{tabular}


Table 2: TS triad census

\begin{tabular}{|c|c|c|c|c|c|c|c|c|c|c|c|c|c|c|c|c|c|c|}
\hline & \multirow{2}{*}{$\begin{array}{l}\text { Model } \\
\text { Type }\end{array}$} & \multicolumn{2}{|c|}{ Balance } & \multirow{2}{*}{$\begin{array}{c}\text { Clusterability } \\
003\end{array}$} & \multicolumn{5}{|c|}{ Ranked Clusters } & \multirow{2}{*}{$\begin{array}{c}\text { Transitivity } \\
012\end{array}$} & \multicolumn{2}{|c|}{$\begin{array}{l}\text { Hierarchical } \\
\bar{M} \text {-Clusters }\end{array}$} & \multicolumn{5}{|c|}{ Forbidden } & \multirow[t]{2}{*}{$\chi^{2}$} \\
\hline & & 102 & 300 & & 021D & $021 \mathrm{U}$ & $030 \mathrm{~T}$ & $120 \mathrm{D}$ & $120 \mathrm{U}$ & & $120 \mathrm{C}$ & 210 & $021 \mathrm{C}$ & 111D & $111 \mathrm{U}$ & $030 \mathrm{C}$ & 201 & \\
\hline \multirow[t]{2}{*}{ AUS } & ni & 4 & 0 & 34 & 119 & 86 & 147 & 4 & 26 & 109 & 1 & 3 & 12 & 3 & 12 & 0 & 0 & $759.5^{*}$ \\
\hline & (ni-ei)/ei & -0.89 & -1 & -0.19 & 2.24 & 1.34 & 2.72 & -0.62 & 1.44 & -0.2 & -0.95 & -0.74 & -0.84 & -0.92 & -0.7 & -1 & -1 & \\
\hline \multirow[t]{2}{*}{ CAN } & ni & 7 & 1 & 29 & 159 & 63 & 172 & 10 & 11 & 88 & 1 & 0 & 9 & 3 & 7 & 0 & 0 & $1068.9^{*}$ \\
\hline & $($ ni-ei $) / e i$ & -0.81 & -0.16 & -0.26 & 3.35 & 0.72 & 3.21 & -0.12 & -0.04 & -0.33 & -0.96 & -1 & -0.88 & -0.93 & -0.83 & -1 & -1 & \\
\hline \multirow[t]{2}{*}{ CZE } & ni & 1 & 2 & 6 & 110 & 73 & 252 & 21 & 48 & 23 & 3 & 4 & 7 & 3 & 6 & 0 & 1 & $1390.8^{*}$ \\
\hline & (ni-ei)/ei & -0.97 & -0.57 & -0.61 & 2.53 & 1.34 & 3.95 & 0.01 & 1.3 & -0.7 & -0.93 & -0.88 & -0.89 & -0.94 & -0.88 & -1 & -0.95 & \\
\hline \multirow[t]{2}{*}{ ESP } & ni & 5 & 2 & 7 & 87 & 89 & 229 & 9 & 44 & 49 & 2 & 6 & 11 & 4 & 16 & 0 & 0 & $1122.3^{*}$ \\
\hline & (ni-ei)/ei & -0.85 & -0.43 & -0.64 & 1.65 & 1.71 & 3.64 & -0.52 & 1.37 & -0.44 & -0.95 & -0.79 & -0.83 & -0.92 & -0.68 & -1 & -1 & \\
\hline \multirow[t]{2}{*}{ FIN } & ni & 13 & 0 & 58 & 166 & 25 & 130 & 15 & 10 & 94 & 5 & 7 & 10 & 4 & 23 & 0 & 0 & $842.0^{*}$ \\
\hline & (ni-ei)/ei & -0.65 & -1 & 0.27 & 3.51 & -0.32 & 2.4 & 0.51 & 0.01 & -0.34 & -0.75 & -0.32 & -0.86 & -0.9 & -0.4 & -1 & -1 & \\
\hline \multirow[t]{2}{*}{ FRA } & $\mathrm{ni}$ & 1 & 0 & 48 & 170 & 37 & 165 & 2 & 10 & 109 & 1 & 0 & 17 & 0 & 0 & 0 & 0 & $1153.6^{*}$ \\
\hline & (ni-ei)/ei & -0.97 & -1 & -0.06 & 3.61 & 0 & 3.56 & -0.77 & 0.13 & -0.27 & -0.94 & -1 & -0.77 & -1 & -1 & -1 & -1 & \\
\hline \multirow[t]{2}{*}{ GER } & ni & 3 & 0 & 36 & 169 & 58 & 158 & 8 & 16 & 96 & 1 & 2 & 3 & 3 & 7 & 0 & 0 & $1070.5^{*}$ \\
\hline & $($ ni-ei)/ei & -0.92 & -1 & -0.15 & 3.6 & 0.58 & 2.99 & -0.25 & 0.5 & -0.3 & -0.95 & -0.83 & -0.96 & -0.92 & -0.82 & -1 & -1 & \\
\hline \multirow[t]{2}{*}{ ITA } & ni & 3 & 0 & 14 & 136 & 108 & 228 & 11 & 20 & 33 & 0 & 1 & 0 & 4 & 2 & 0 & 0 & $1471.8^{*}$ \\
\hline & (ni-ei)/ei & -0.91 & -1 & -0.44 & 2.93 & 2.12 & 3.86 & -0.31 & 0.26 & -0.68 & -1 & -0.95 & -1 & -0.91 & -0.96 & -1 & -1 & \\
\hline \multirow[t]{2}{*}{ JPN } & ni & 9 & 0 & 56 & 146 & 43 & 113 & 8 & 16 & 123 & 4 & 4 & 14 & 6 & 15 & 1 & 2 & $640.0^{*}$ \\
\hline & (ni-ei)/ei & -0.76 & -1 & 0.06 & 2.96 & 0.17 & 2.19 & -0.06 & 0.87 & -0.2 & -0.77 & -0.51 & -0.81 & -0.83 & -0.58 & -0.92 & -0.77 & \\
\hline \multirow[t]{2}{*}{ KOR } & ni & 2 & 1 & 21 & 146 & 44 & 175 & 7 & 50 & 66 & 9 & 8 & 7 & 9 & 14 & 0 & 1 & $994.2^{*}$ \\
\hline & (ni-ei)/ei & -0.94 & -0.61 & -0.13 & 3.25 & 0.28 & 2.69 & -0.57 & 2.06 & -0.34 & -0.72 & -0.65 & -0.9 & -0.81 & -0.7 & -1 & -0.94 & \\
\hline \multirow[t]{2}{*}{ NLD } & ni & 0 & 0 & 83 & 152 & 39 & 106 & 2 & 9 & 148 & 0 & 1 & 5 & 2 & 13 & 0 & 0 & $766.1^{*}$ \\
\hline & $($ ni-ei $) / e i$ & -1 & -1 & 0.09 & 3.27 & 0.1 & 2.77 & -0.64 & 0.62 & -0.18 & -1 & -0.77 & -0.93 & -0.93 & -0.54 & -1 & -1 & \\
\hline \multirow[t]{2}{*}{ POL } & ni & 3 & 2 & 4 & 88 & 56 & 270 & 6 & 64 & 28 & 9 & 7 & 10 & 0 & 10 & 3 & 0 & $1421.8^{*}$ \\
\hline & (ni-ei)/ei & -0.9 & -0.64 & -0.7 & 1.93 & 0.87 & 4.23 & -0.73 & 1.88 & -0.6 & -0.8 & -0.82 & -0.83 & -1 & -0.81 & -0.83 & -1 & \\
\hline \multirow[t]{2}{*}{ UK } & ni & 6 & 1 & 37 & 115 & 65 & 171 & 11 & 8 & 127 & 2 & 0 & 5 & 2 & 10 & 0 & 0 & $846.1^{*}$ \\
\hline & (ni-ei)/ei & -0.84 & 0.12 & -0.19 & 2.12 & 0.76 & 3.47 & 0.11 & -0.19 & -0.11 & -0.9 & -1 & -0.93 & -0.95 & -0.74 & -1 & -1 & \\
\hline \multirow[t]{2}{*}{ US } & ni & 3 & 1 & 17 & 142 & 78 & 209 & 13 & 20 & 44 & 5 & 1 & 4 & 11 & 11 & 0 & 1 & $1203.0^{*}$ \\
\hline & $($ ni-ei)/ei & -0.91 & -0.59 & -0.32 & 3.11 & 1.26 & 3.45 & -0.18 & 0.26 & -0.57 & -0.84 & -0.95 & -0.94 & -0.77 & -0.77 & -1 & -0.94 & \\
\hline
\end{tabular}

* Null hypothesis (no balance-theoretic model) rejected at $0.1 \%$ significance level.

(ni-ei)/ei = Relative difference between the actual number of triads (ni) and that expected by chance (ei) 
the null hypothesis of a no balance-theoretic model (Section 3.2, point vi). All the 15 TSs we have addressed, even those referring to relatively less developed areas in innovative terms, namely the former socialist countries, reveal a certain degree of organization into techno-economic clusters. Far from representing isolated techno-economic "atoms", their constituent sectors always rank or cluster among them to a certain extent.

More precisely, as it clearly emerges from the relative differences between the actual number of triads and that expected by chance, in all the cases the "ranked clusters model" (Section 3.2, point iii) is the one that better fits the data. It has to be stressed that these results are quite robust and do not change significantly altering the cut-off: the present analysis has been accomplished for all the cut-offs of Section 4.5 and the main results do not change. Moreover, by means of generalized blockmodeling (Doreian et al., 2005), the model of ranked clusters has been also tested against the alternative hypothesis of a core-periphery structure and the former model has performed better, returning the lowest error score at all the chosen cut-offs. Therefore, in all the 15 TSs investigated, intersectoral clusters of techno-economic nature emerge in a strongly hierarchical manner.

This is an extremely interesting result, which corroborates the OECD hypothesis of "reduced systems" within nation-wide innovation systems (OECD, 1999, 2001). ${ }^{14}$ Indeed, the division of labour in the innovative process of national TSs creates groups of sectors whose role, here in terms of techno-economic diffusions, is of different importance. Some clusters (we do not know how many and which yet) are more pervasive than others in "innervating" the hosting TS, and thus locate at a higher level. Some others are instead more dependent on external direct techno-economic flows for their techno-economic role in the same TS, and thus locate at a lower level. In other words, the 15 TSs we have investigated are in principle quite "complex", as they host "cohesive" groups of sectors organized into TS-wide hierarchies which are the most complete in terms of direct techno-economic relationships: high ranked meso-economic clusters, so to say "pervasive", are so because the R\&D embodied flows which depart from them on average reach directly all the meso-economic clusters of lower rank, so to say "dependent". On the other hand, we do not know yet how complex our 15 TSs are. This requires us to identify for them the actual number of what we have called truly systemic clusters, a task to which we will dedicate in the following.

\footnotetext{
14 "A national economy consists of several reduced-form innovation systems represented by various distinct industrial clusters. This implies that any country overall innovation system would necessarily include composite features of innovation underway in its fewto-many industrial clusters, depending on the size and the complexity of the national economy." (OECD, 2001, p.9)
} 


\section{4 "Reduced technological systems"(ReTS) in technological systems (TS)}

\subsubsection{ReTSs and TS "complexity"}

At the outset, let us observe that the present cut-off reduces the "complexity" of the 15 TSs substantially (Figures 3, 4 and 5). In general, they host just one cluster which, according to the SC criterion (see Section 3.3), can be qualified as ReTS. ${ }^{15}$ In all the TSs, therefore, inherently sub-systemic relationships in general polarize in just one portion of the correspondent TS. This is a quite interesting result. Not only is the geographical space of a nation often too large for a system of innovation to be associated to it, as regional economics and local studies have realized since long, but the same holds true also for the techno-economic space of a national economic system: the functional boundaries of an actual TS are apparently narrower than those delimited by the input-output table of one country. ${ }^{16}$

Interesting insights emerge by considering the number of sectors in the ReTSs identified. The case of Poland (Figure 5(c)), for example, appears quite idiosyncratic. Apart from two sectors (Sector 1 and 14), all the others communicate diffusely among them in terms of techno-economic flows. To the point that none of them emerge as pivotal, or core, in the diffusion process with respect to the others. Indeed, not only does the Polish TS appears very dense, but the correspondent TS is also very "flat", as traditionally pivotal technological sectors, such as for example chemicals (Sector 5) or machinery and equipment (Sector 11), do not have a higher-level position with respect to the others.

Still quite interestingly, and with some other exceptions (e.g. Spain), the TSs with the best recent innovative performances of our group, at least in terms of R\&D intensity in the correspondent years (OECD, 2003), show ReTSs encompassing at least half of the 16 sectors of the reference disaggregation, that is: Korea (Figure 3(a)), Japan and Finland (Figures 3(e) and $3(\mathrm{f})$ ), and the US (Figure 5(b)). Finally, relatively smaller are the ReTSs which can be identified in the other countries, where the number of sectors among which techno-economic flows circulate diffusely spans from three, in France (Figure 4(b)) and the Netherlands (Figure 4(a)), to five, in Norway (Figure 5(a)). A result that, with the partial exception of France, is in line with the evidences on the low degree of connectivity of the correspondent

\footnotetext{
${ }^{15} \mathrm{SCs}$ are identified by groups of nodes with the same color. Of course, the density of a TS and the number of its ReTS are somehow related: a higher density implies a larger number of flows above the cut-off, and thus a greater probability to have relationships which are able to fuel SCs in a network. However, this relationship is just potential and does not necessarily turn into actual. A glance at the 15 oriented graphs and the illustrative comparison between France and Japan (with exactly the same density) confirm this point.

${ }^{16}$ To be sure, three exceptions "confirm" this result, that is, Australia (Figure 3(c)), Czech Republic (Figure 3(d)), and Italy (Figure 4(f)), where the "reduced TSs" that can be identified are two, still a low number.
} 
systems of innovation (Leoncini and Montresor, 2000b; Ørstavik and Nås, 1998).

\subsubsection{ReTSs and TS structures}

The number and the size of the ReTSs identified provides us with a basis to detect different TS structures and group the 15 TSs themselves accordingly. A visual inspection of the oriented graphs (Figures 3,4 and 5) suggests to us four structures to which a fifth group of idiosyncratic ones can be added. ${ }^{17}$

(i) A first TS structure we can recognize is that of a "diamond-like" TS, dominated by a large ReTS, "innervated" by the techno-economic flows of just one or two higher sectors, and only directly: in relative terms, such a techno-economic cluster can thus be deemed nearly selfsufficient. Its embodied R\&D pervades, to an increasing extent, other sectors disposed at a number of different levels below it, up to a unique mostly dependent sector (the lower apex of the diamond). Accordingly, the degree to which the other sectors depend on the ReTS appears differentiated.

Although with sectoral differences, in our application this is the structure of Korea and Spain (Figures 3(a) and 3(b)), where electrical and optical instruments (Sector 11), along with other transport equipments (Sector 13) in Spain, are the only sectors the ReTS needs to draw on for "circulating" technological flows intensive of natural resources (Sectors 4 and 15), chemicals (Sectors 5 and 6) and metals (Sectors 8, 9 and 10)).

A sort of degeneration of the diamond structure can also be found in the cases of Australia and Czech Republic (Figures 3(c) and 3(d)), where the diamond contour is less "shaped" and an additional two-sector ReTS of intermediate level is identified. Quite interestingly, motor vehicles (Sector 12) and other transport equipment (Sector 13) "fuel" the higher level ReTS in the Czech Republic, while they are rather reached by its techno-economic flows in Australia (at the closest lower level): a sign of the different maturity the means of transport technology has in the two TSs.

(ii) A second, pentagon-like structure can be identified in those TSs with a large ReTS, "fuelled" by no more than two other sectors as in the previous case, but, unlike the previous case, both directly and indirectly by one of them (the upper apex of the pentagon). Accordingly, the correspondent techno-economic cluster can be deemed less self-sufficient than that of the previous structure. The ReTS still pervades to an

\footnotetext{
${ }^{17}$ Of course, the way we have grouped the TS structures is somehow subjective, as different TS clusters could be possibly identified by looking at different aspects. In the following, different structures are associated to different geometrical figures, with a large benefit of hindsight and a purely recognizing value.
} 
increasing extent other sectors, but here just at other two different levels below it. Their dependency on the ReTS is thus more homogeneous than in the previous case.

Although with differences, such a structure is shared by Japan and Finland (Figures 3(e) and 3(f)), where a large ReTS receives techno-economic flows by one pivotal sector only - chemicals (Sector 5), in the Japanese case, electrical and optical instruments (Sector 11), in the Finnish one - but here both directly and indirectly. Few are the sectors outside the ReTS - mainly with a "supplier-dominated" nature (Sectors 14 and 2)- among which we find, in both cases, the manufacturing transport sectors (Sectors 12 and 13), although other transports is mostly dependent in Japan only.

Although non strictly pentagon-like, to this group of TSs we can also add that of Germany (Figure 4(e)), which differs from that of Finland and Japan for two variations: the shift of transport equipments (Sector 13) from below to above the ReTS, a larger "base" of dependent sectors where we "exceptionally" find also coke, petroleum and nuclear products (Sector 4).

(iii) A sort of different, hexagon-like version of the previous structure, is represented by TSs whose "reduced TSs" are still "innervated" by two higher sectors (both directly and indirectly by one of them), but with a smaller size and innovating a larger number of sectors, to a variable extent up to a unique maximum dependent sector.

This is the structure of the Dutch and of the French TSs (Figures 4(a) and 4(b)), where electrical and optical instruments (Sector 11), in the former case, machinery and equipment (Sector 10), in the latter, provide the correspondent ReTS with substantial techno-economic flows, both directly and indirectly. Although the technological nature of this three-sector ReTS is quite different in the two cases, and somehow reflecting their different specialization models, strong similarities can be identified by looking at their dependent sectors: in particular, in both cases we find the non (strictly) manufacturing sectors (Sectors 15 and 16) of the disaggregation.

(iv) A fourth star-like structure can be associated to the TSs in which the ReTS has an intermediate size and gets thus innervated, both directly and indirectly, by a number of sectors which is not much smaller than those it innervates in turn. Once compared with the previous structures, its self-sufficiency is thus lower, while the dependency of the remaining sectors from it is relatively more homogeneous.

This is the case of Canada and the UK (Figures 4(c) and 4(d)), where a techno-economic core of 3 and 4 sectors, respectively, is characterized by heterogeneous (in terms of levels) innovative diffusions. In both cases the ReTS is identified by the metal-based sectors of our disaggregation (Sector 
8, 9 and 10) (with the addition of electricity, gas and water supply (Sector 15), in the UK), pointing to the importance of embodied innovation flows in identifying system clusters.

(v) A final cluster of TSs is identified by structures which appear relatively idiosyncratic, and thus heterogeneous both among them and with respect to the others.

This is, first of all, the case of the US (Figure 5(b)), out of whose ReTS we just find 8 sectors, and along just two other superior and inferior hierarchical lines. Quite interestingly, these are the 3 most science-based of the disaggregation (Sectors 5, 11 and 13), which supply the ReTS, and the 5 most supplier-dominated ones, which are instead supplied by it in techno-economic terms (Sectors 1, 2, 14, 15 and 16).

Quite idiosyncratic appears also the Polish TS (Figure 5(c)), which in fact collapses in a sort of super ReTS, from which only two sectors are excluded as purely dependent: food, beverages and tobacco (Sector 1) and residual manufacturing (Sector 14). Given the relative small size of the techno-economic flows retained, this is not necessary inconsistent with the very poor innovative performances of the country (e.g. in terms of $R \& D$ intensity), where networking among SMEs has been recently put on the top of the agenda (CIMPAN, 2003). ${ }^{18}$

Remarkable is also the case of Italy (Figure 4(f)), whose larger ReTS (out of the two) locates at a quite low level, revealing the presence of a metalbased sub-system (Sectors 8, 9 and 10), which needs the techno-economic contributions of a remarkable number of sectors and, in particular, of a higher-level and smaller ReTS which is based on the energy-based sectors (Sectors 4 and 15).

Finally, Norway (Figure 5(a)) has a ReTS which locates at an even lower level than Italy in the correspondent oriented graph. Such a ReTS thus reveals the need of several techno-economic injections to be set at work, along with the "capacity" of fueling just one sector (i.e. Sector 4, coke, refined petroleum products and nuclear fuel) in addition to the usual residual manufacturing and service sectors (Sector 14, 15 and 16).

\subsubsection{ReTSs and cliques}

As a way to complement the previous analysis, it might be interesting to analyze which of the clusters we have identified as ReTS actually qualify

\footnotetext{
${ }^{18}$ In 2004, the Polish R\&D intensity was $0.53 \%$, just above Mexico and Slovak Republic (OECD, 2006). However, since the middle '90s the local authorities have been trying to implement at least the downstream part of a still prospective system of innovation. The National SME Services Network (KSU) (http://ksu.parp.gov.pl/lista.html), a group of 180 co-operating business counselling centres all over the country for supporting development of the SME sector, is the most remarkable example of these efforts.
} 


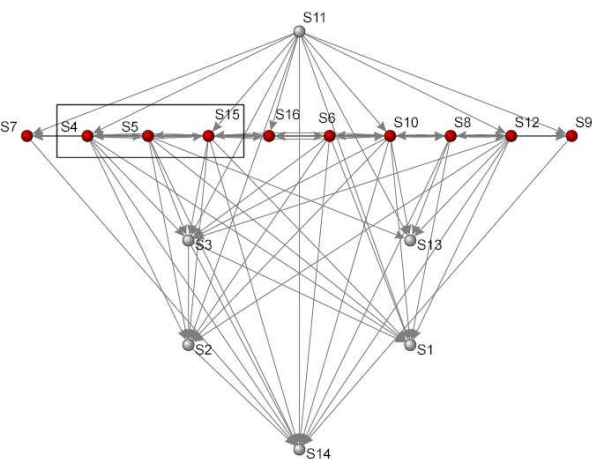

(a) Korea

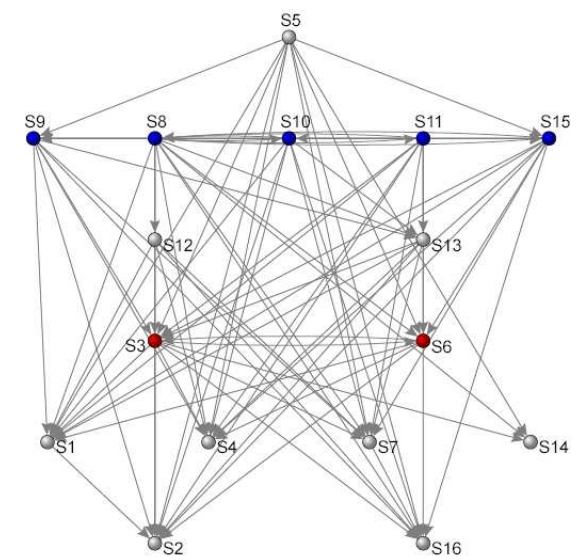

(c) Australia

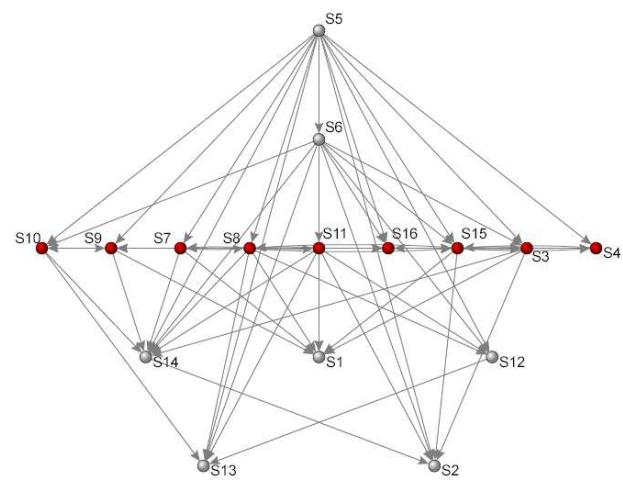

(e) Japan

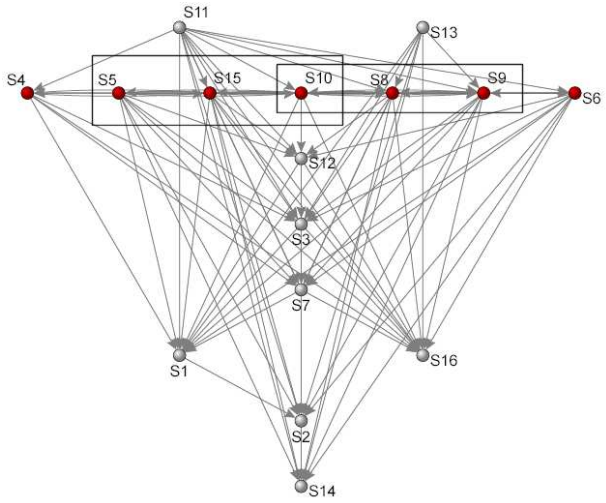

(b) Spain

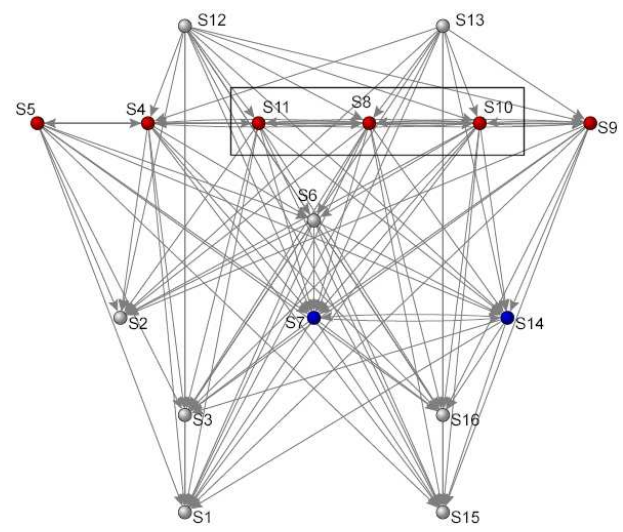

(d) Czech Republic

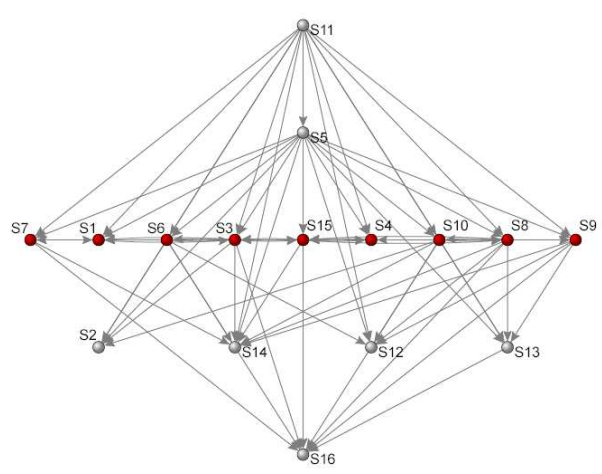

(f) Finland

Figure 3: Oriented graphs 


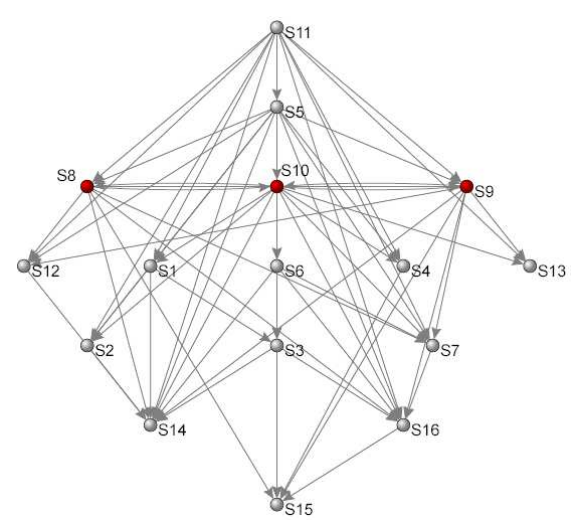

(a) Netherlands

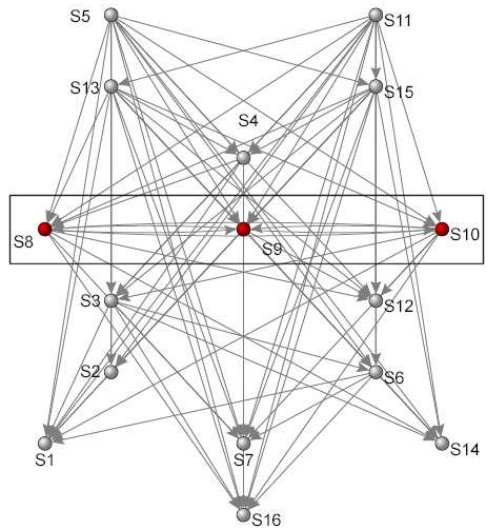

(c) Canada

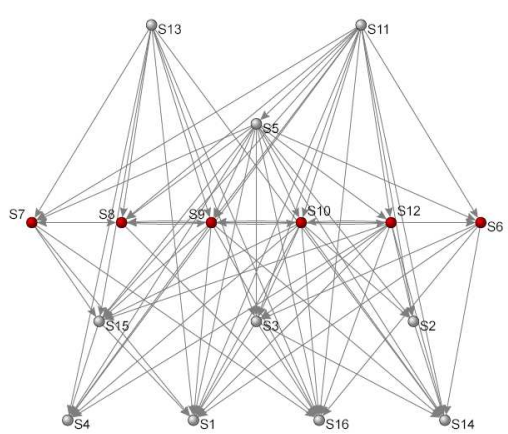

(e) Germany

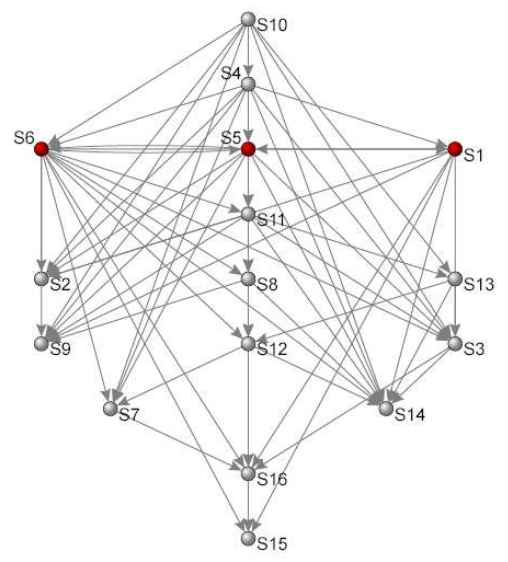

(b) France

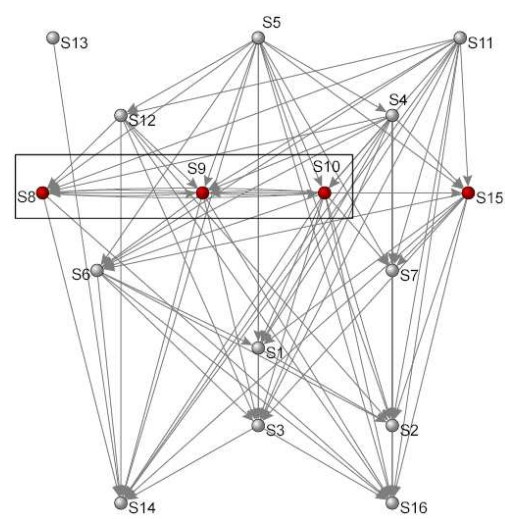

(d) United Kingdom

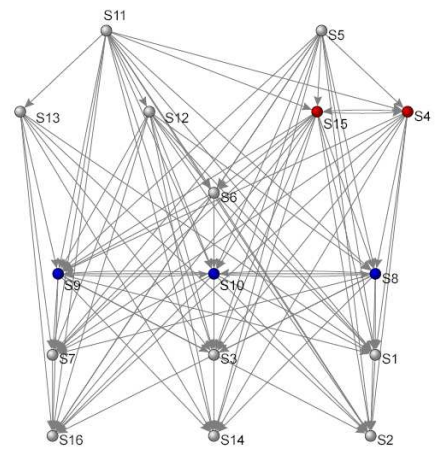

(f) Italy

Figure 4: Oriented graphs II 


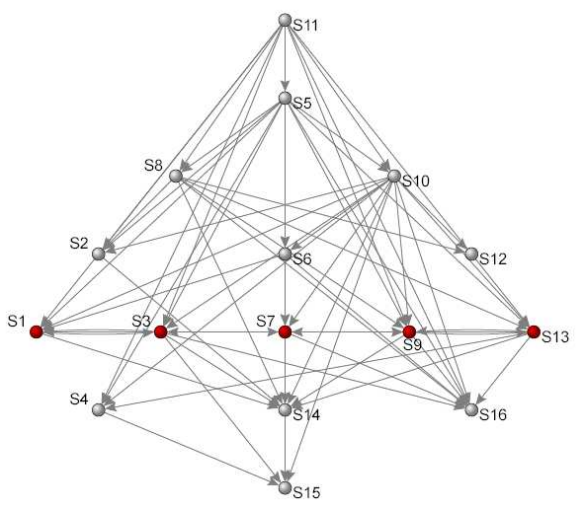

(a) Norway

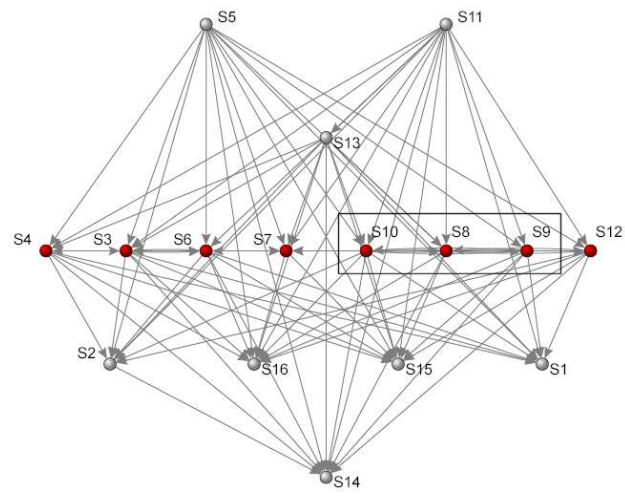

(b) United States

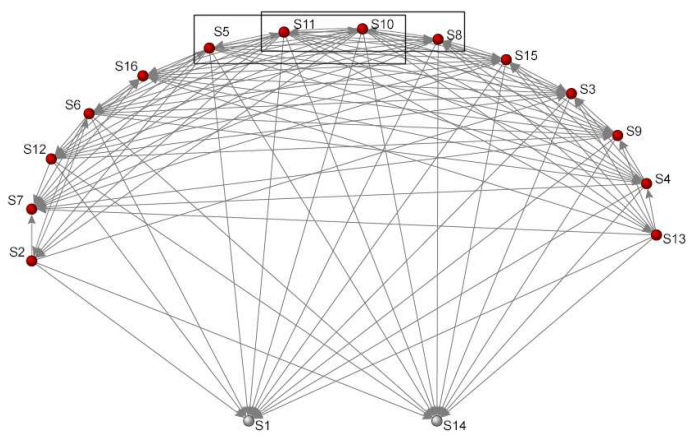

(c) Poland

Figure 5: Oriented graphs III

also as cliques, or contain cliques. In these cases the ReTS is in fact mostly systemic, since each sector in it both supplies and is supplied by any other. Quite interestingly, the clique analysis helps in better qualifying the clusters of TSs of the previous section.

For the present cut-off $(t=.0111)$, cliques can be found in 7 out of the 15 TS considered (in Figures 3-5, whenever present, cliques have been "boxed" in a rectangular). In the pentagon-like structures (Section 4.4.2, point ii) of Japan, Finland and Germany, the hexagon-like ones (Section 4.4.2, point iii) of the Netherlands and France, and in those of Australia, Italy and Norway, the techno-economic clusters we have identified do not host sectors with mutual relationships: the ReTs at the core of their TSs do not comprehend any more systemic "super-core".

As for the other seven TSs, it should be first noticed that, with the relevant exception of the Korean TS, the cliques identified always include some or all of the metal-based sectors of our disaggregation, that is: basic metals (Sector 8), fabricated metal products (Sector 9) and machinery and equipment (Sector 10). Given that these are the sectors which most resort 
to embodied kind of technological exchanges, on the basis of which clusters have been detected, this result was somehow expected. But not necessary, as the Korean TS shows.

In the "diamond-like" TSs (Section 4.4.2, point i) of Spain and Czech Republic (Figures 3(b) and 3(d)), these sectors clique along with few others more - Sectors 5 and 15 in Spain, Sector 11 in the Czech Republic (which replies Sector 9) - and actually constitute a sort of "super-core" within the wider ReTS. Of a different nature is instead the super-core we find in the Korean diamond, exclusively based on energy products (Sector 4), chemicals (Sector 5) and public-utilities (Sector 15).

In Canada (Figure 4(c)) and the UK (Figure 4(d)), the two "star-like" structures identified above (Section 4.4.2, point iv), the clique of the three metal-based sectors actually covers the whole ReTS (which in UK comprehends in addition also Sector 15). Conversely, in the two idiosyncratic structures of Poland (Figures 5(c)) and the US (Figures 5(b)), the same three sectors constitute a small "island" of reciprocal techno-economic relationships in two of the widest ReTSs.

\subsection{A (sort of) sensitivity analysis}

Table 3 reports the number and the composition of the clusters identified for cut-offs other than $t=.0111$, both below and above it (see also Figure 2). Once more, these values have been selected in a heuristic way, by looking for relevant changes in the TS structures.

In general, let us observe that, as expected, very few results are robust with respect to the size of the techno-economic flows considered. For sure, this is the case of the Korean TS, whose diamond-like structure persists until relatively large flows only are retained $(t=.0215)$. Conversely, the ReTS of the Spanish diamond vanishes more rapidly, although linearly (i.e. with no structural changes) with the reduction of its density. That of Korea is thus a TS systemically fuelled by a large ReTS of sectors, from which the others depend to a hierarchically increasing extent. ${ }^{19}$

Out of the three pentagon-like structures, the most robust appears that of Finland, whose ReTS is nearly entirely cliqued for a slightly smaller cut-off $(t=.009)$ and in which wood, paper and printing (Sector 3) and electricity, gas and water (Sector 15) remain cyclically related also by retaining quite large techno-economic flows (e.g. for $t=.0292$ and $t=.0317$ ). Quite interestingly, unlike in the other TSs, also food, beverage and tobacco (Sector 1) and coke, petroleum and nuclear products (Sector 4) remain networked

\footnotetext{
${ }^{19}$ As for the other diamond-like TSs, a two-ReTS structure appears more a trait of the Czech Republic than Australia, although in the former the clusterization of the technoeconomic space shrinks more rapidly by increasing $t$, and reduces to the metal-based sectors of the disaggregation (Sectors 8,9 and 10). Their clique in the Czech TS is also quite permanent.
} 
for a large array of $t$ s. This is another important result, which suggests how the techno-economic injections of a higher level sector allow to relatively low-tech ones to enter in cyclical clusters also of a certain importance. ${ }^{20}$

Among the hexagon-like TSs, the French one emerges for its idiosyncratic and stable chemical-based cluster (Sector 5 and 6), in which food and beverages (Sector 1) play a part until too large flows are retained. Conversely, the Dutch ReTS rapidly shrinks to the usual metal based sectors, which are however unable to circulate relatively large techno-economic flows.

Sectors 8, 9 and 10 are systematically pivotal also for the star-like structures of the UK and Canada. To be sure, these two, and the UK in particular, are the TSs whose systemic techno-economic flows drop more substantially by departing from $t=.0111$ as cut-off. As in the Netherlands, the metal-based ReTS vanishes as a whole when relative large flows only are considered.

Some final remarks are due to for the idiosyncratic TS structures. The US, first of all, adds to Finland and France as a TS where clusterization is traceable also for relatively large cut-offs (that is, larger than $t=.025$ ). Quite interestingly, however, an important result is that the hierarchical structure of the American TS is quite sensitive to the size of the retained techno-economic flows. In particular, we find cases of sectors which, by increasing $t$, leave a ReTS to constitute another "independent" one (consider Sectors 5 and 11 for $t=.005$, and Sectors 3 and 6 for $t=.0125)$. The hierarchical nature of this TS appears thus less structural than that of other TSs. $^{21}$

A last interesting result is represented by the Italian TS. Indeed, its pivotal clustering sectors - that is Sectors 4, 6, 8, 9, 10 and 15 - emerge as soon as techno-economic flows of a certain relevance are considered (i.e. for $t=.009$ ). By increasing the flow size, rather than shrinking (substantially), the same cluster decouple into the two ReTSs we have identified for $t=.0111$, and remains so also for larger technological exchanges (e.g. for $t=.0125$ ). For even larger ones (e.g. $t=.0215)$, instead, the sectors of the notable Italian specialization model (i.e. fabricated metal products (Sector 9) and non-electrical machinery (Sector 10)) remain the only one to enable cyclical

\footnotetext{
${ }^{20}$ Let us also observe that, before exiting from the list of the clustered sectors, Sectors 8 and 10 come to constitute in Finland a cyclical relationship distinguished from that based on Sectors 3 and 15. As for the other "pentagons", while the Japanese ReTS "linearly" shrinks to a resource-intensive clusters - made up of wood, paper and printing (Sector 3), electricity, gas and water (Sector 15) and construction (Sector 16) - the German TS looses its upper ReTS for techno-economic flows of medium size $(t=.0125)$ and shrinks more suddenly, for larger ones $(t=.0215)$, to a cluster based on motor-vehicles (Sector 12) and machinery (Sector 10).

${ }^{21} \mathrm{~A}$ similar switch can be observed in the Polish TS, where Sectors 3, 15 and 16 separate from the largest ReTS for $t=.0125$ before exiting from the clustered portion of the TS, which vanishes, completely and suddenly, for $t=.0215$.
} 
cluster relationships. $^{22}$

\section{Conclusions}

Although less visible than the territorial one, the "techno-economic space" represents an important meso-economic dimension along which innovation activities can cluster. Providing the underlying relationships are qualified, these clusters can actually be seen as "reduced technological systems" (ReTSs), that is as subsystems which make their hosting technological system (TS) inherently complex. Accordingly, these subsystems forge the structure of a national TS and become an inescapable element in evaluating it, especially in comparative exercises.

By drawing on previous related works, in the paper we have suggested to "map" the techno-economic space of a certain TS by building up the correspondent matrix of embodied R\&D intersectoral flows. Along the same research line, we have applied network analysis techniques to these matrices in order to "scan" the techno-economic space of a TS. As an added-value to the same literature, instead, we have applied some network-analysis techniques of social grouping to investigate the patterns according to which innovations cluster in the techno-economic space, and which of the resulting clusters actually qualify as systemic in nature (that is, as a ReTS).

Once applied to a set of 15 OECD TSs for the middle '90s, this analysis provides us with novel insights about the structural similarities and dissimilarities that can be detected among them. At the outset, the techno-economic activities of all these 15 TSs organize hierarchically, with clusters of sectors of different importance in the relative diffusion process. Other hypotheses of clusterization are in fact significantly rejected.

Interesting results also emerge when, with respect to techno-economic flows of a given size, clusters are looked for and selected according to the heterarchical nature of their relationships: that is, when ReTSs are identified on the basis of the cyclical nature of the relationships which survive by dichotomizing the relevant intersectoral R\&D matrix. Indeed, on this basis, the 15 TSs can be clustered among them according to oriented graphs of similar structure, whose meaning only marginally overlaps with what suggested by other (possibly less systemic) empirical studies. Korea and Spain, for example, although radically different in institutional terms, share a "diamond-like" techno-economic space dominated by a wide cluster of cyclically related sectors, drawing on one or two superior sectors and innervating all the others to an increasingly hierarchical extent.

\footnotetext{
${ }^{22}$ A certain robustness is also shown by the Norwegian TS, whose low-level ReTS already emerges for quite low cut-off values, remains centered on the identified sectors (i.e. Sectors 1, 3, 7, 9 and 13), but just until appreciable techno-economic flows only are considered (e.g. for $t=.0125$ ).
} 
Table 3: Strong components and cliques at different cut-offs

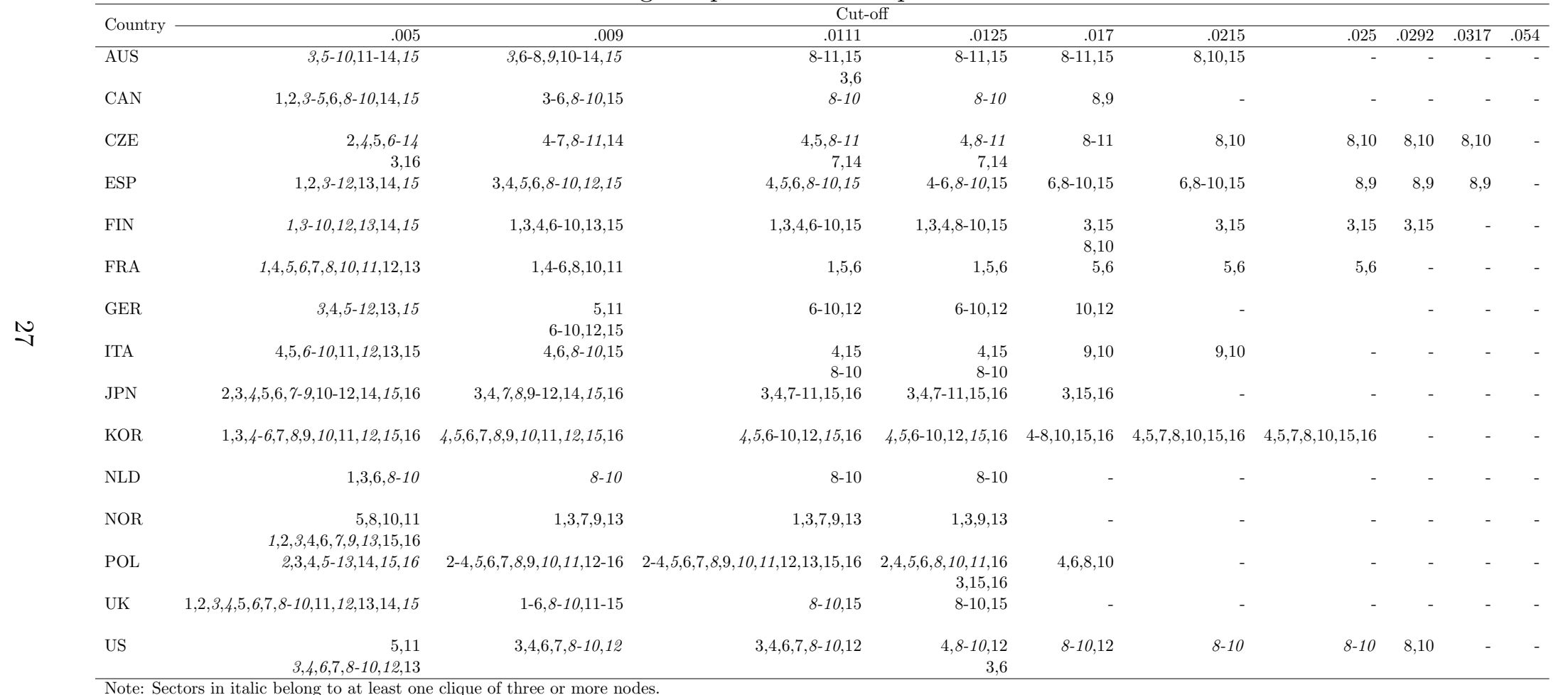


As in other related works, the sensitivity of the results to the selected cutoff value has been considered through an appropriate analysis of the density distributions revealed by the 15 TSs: this time, for a much larger number of cut-offs. The size of the techno-economic flows has been thus shown to play an important role in shaping the clusters of the investigated TSs, but results of a certain robustness have been obtained too. The size-contingent hierarchical structure of the US TS, for example, contrasts the structural configuration displayed by the Korean one.

In concluding, the question of how to relate the results of this paper with others on the TSs (or the NSIs) we have investigated should be clarified. As we have repeatedly shown, some of the results of our analysis can be read by considering the embodied and input (R\&D) nature of the innovation flows we have retained. Some others are instead related to what we know about the specialization model of the relevant country, both in terms of production and innovation. In general, however, given the special features of the technoeconomic space we have referred to, the analysis of innovation clustering we have pursued offers new results which should be used in integrating, rather than supporting or contrasting, previous and future knowledge about the structure and functioning of TSs.

\section{References}

Batagelj, V., Mrvar, A. and De Nooy, W. (2005) Exploratory Social Network Analysis with Pajek (Cambridge: Cambridge University Press).

Chang, P.-L. and Shih, H.-Y. (2005) Comparing patterns of intersectoral innovation diffusion in Taiwan and China: A network analysis, Technovation, $25(2)$, pp. $155-169$.

CIMPAN (2003) Inventory of the Polish National Innovation System (NIS), Tech. rep., Centre for Industrial Management Polish Academy of Sciences European Integration Exploratorium, Poland.

Cooke, P., Gomez-Uranga, M. and Etxebarrria, G. (1997) Regional innovation systems: institutional and organisational dimensions, Research Policy, 26, pp. $475-491$.

Davis, J. A. and Leinhardt, S. (1972) The structure of positive interpersonal relations in small groups, in: J. Berger (Ed.) Sociological Theories in Progress, vol. 2 (Boston: Houghton Mifflin), pp. 218-251.

DeBresson, C. (1996a) The inter-industrial analysis of innovative activities, in: C. DeBresson (Ed.) Economic Interdependence and Innovative Activity. An Input-Output Analysis (Cheltenham: Edward Elgar), pp. 66-78. 
DeBresson, C. (1996b) New locational factors for the creation of technical knowledge, in: C. DeBresson (Ed.) Economic Interdependence and Innovative Activity. An Input-Output Analysis (Cheltenham: Edward Elgar), pp. 227-236.

DeBresson, C. (1996c) Toward stochastic theories of innovative activities, in: C. DeBresson (Ed.) Economic Interdependence and Innovative Activity. An Input-Output Analysis (Cheltenham: Edward Elgar), pp. 308-333.

DeBresson, C. (1996d) Why innovative activities cluster, in: C. DeBresson (Ed.) Economic Interdependence and Innovative Activity. An Input-Output Analysis (Cheltenham: Edward Elgar), pp. 149-165.

DeBresson, C., Sirilli, G., Lemay, J., Hu, X. and Luk, F. (1996) Innovative clusters in Italy (1981-1985), in: C. DeBresson (Ed.) Economic Interdependence and Innovative Activity. An Input-Output Analysis (Cheltenham: Edward Elgar), pp. 165-189.

Diestel, R. (2005) Graph Theory (New York: Springer-Verlag Heidelberg), $3^{\text {rd }}$ edn.

Doreian, P., Batagelj, V. and Ferligoj, A. (2000) Symmetric-acyclic decompositions of networks, Journal of Classification, 17, pp. 3-28.

Doreian, P., Batagelj, V. and Ferligoj, A. (2005) Generalized Blockmodeling (Cambridge University Press).

Edquist, C. and Johnson, B. (1997) Institutions and organisations in systems of innovation, in: C. Edquist (Ed.) Systems of Innovation. Technologies, Institutions and Organisations (London: Pinter Publishers), pp. 41-63.

Edquist, C. and McKelvey, M. (Eds.) (2000) Systems of Innovation: Growth, Competitiveness and Employment (Cheltenham, UK: Edward Elgar Publishing).

European Commission (2006) Innovation and Innovation Policy in Spain, Innovation Policy in Europe: Trend Chart, European Commission.

Hill, K. (2006) Universities in the U.S. National Innovation System, Productivity and Prosperity Project, Ariziona State University.

Holland, P. and Leinhardt, S. (1970) A method for detecting structure in sociometric data, American Journal of Sociology, 70, pp. 492-513.

Holland, P. and Leinhardt, S. (1971) Transitivity in structural models of small groups, Comparative Group Studies, 2, pp. 107-124.

Holland, P. and Leinhardt, S. (1975) Local structure in social networks, Sociological Methodology, 1976, pp. 1-45. 
Johnson, B. (1992) Institutional learning, in: B. Lundvall (Ed.) National Systems of Innovation. Towards a Theory of Innovation and Interactive Learning (London: Pinter Publishers), pp. 23-44.

Lave, J. and Wenger, E. (1991) Situated Learning - Legitimate Peripheral Participation (Cambridge: Cambridge University Press).

Leoncini, R. (1998) The nature of long-run technological change: innovation, evolution and technological systems, Research Policy, 27, pp. 75-93.

Leoncini, R., Maggioni, A. and Montresor, S. (1996) Intersectoral innovation flows and national technological systems: network analysis for comparing italy and germany, Research Policy, 25, pp. 415-430.

Leoncini, R. and Montresor, S. (2000a) Classifying technological systems: an empirical application to eight OECD countries, in: P. Saviotti and N. B. (Eds.) Technology and Knowledge: from the Firm to Innovation Systems (Cheltenham: Edward Elgar), pp. 152-173.

Leoncini, R. and Montresor, S. (2000b) Network analysis of eight technological systems, International Review of Applied Economics, 14(2), pp. 213-234.

Leoncini, R. and Montresor, S. (2001) The automobile technological systems. an empirical analysis of four European countries, Research Policy, 30, pp. $1321-1340$.

Leoncini, R. and Montresor, S. (2003a) Intersectoral innovation flows, in: R. Leoncini and S. Montresor (Eds.) Technological Systems and Intersectoral Innovation Flows (Cheltenham: Edward Elgar), pp. 49-73.

Leoncini, R. and Montresor, S. (2003b) The technological system, in: R. Leoncini and S. Montresor (Eds.) Technological Systems and Intersectoral Innovation Flows (Cheltenham: Edward Elgar), pp. 33-49.

Leoncini, R. and Montresor, S. (2003c) Technological Systems and Intersectoral Innovation Flows (Cheltenham: Edward Elgar).

Leoncini, R. and Montresor, S. (2005) Accounting for core and extra-core relationships in technological systems: a methodological proposal, Research Policy, 34, pp. 83-100.

Loasby, B. J. (2000) The division and organisation of knowledge, European Journal of Economic and Social Systems, 14(2), pp. 143-155.

Lundvall, B.-A. (Ed.) (1992) National Systems of Innovation. Towards a Theory of Innovation and Interactive Learning (London: Pinter). 
Malerba, F. (1993) The national system of innovation: Italy, in: R. Nelson (Ed.) National Innovation Systems. A Comparative Analysis (Oxford: Oxford University Press).

Marengo, L. and Sterlacchini, A. (1990) Intersectoral technology flows. Methodological aspects and empirical applications, Metroeconomica, 41, pp. 19-39.

OECD (1999) Boosting innovations, the cluster approach (Paris: OECD).

OECD (2001) Innovative clusters, drivers of national innovation systems (Paris: OECD).

OECD (2003) OECD Science, Technology and Industry Scoreboard 2003 Towards a knowledge-based economy (Paris: OECD).

OECD (2006) Economic Survey of Poland 2006, Tech. rep., OECD, Paris.

Ørstavik, F. and Nås, S. O. (1998) Institutional mapping of the Norwegian system of innovation, STEP Working Paper ISSN 1501-0066.

Porter, M. (2000) Location, competition, and economic development: Local clusters in a global economy, Economic Development Quarterly, 14(1), pp. $15-34$.

Potts, J. (2000) The New Evolutionary Microeconomics (Cheltenham: Edward Elgar).

von Hippel, E. (1976) The dominant role of users in the scientific instrument innovation process, Research Policy, 5, pp. 212-239.

Wasserman, S. and Faust, K. (1994) Social Network Analysis: methods and applications (Cambridge: Cambridge University Press).

Yim, D. S. and Kim, W. D. (2005) The evolutionary responses of Korean government research institutes in a changing national innovation system, Science, Technology 85 Society, 10(1). 


\section{A Country coverage}

\begin{tabular}{lc}
\hline Country & I-O and ANBERD data \\
\hline Australia & 1995 \\
Canada & 1997 \\
Czech Republic & 1995 \\
Finland & 1995 \\
France & 1995 \\
Germany & 1995 \\
Italy & 1992 \\
Japan & 1995 \\
Korea & 1995 \\
Netherlands & 1995 \\
Norway & 1997 \\
Poland & 1995 \\
Spain & 1995 \\
United Kingdom & 1998 \\
United States & 1997 \\
\hline
\end{tabular}

\section{B Sector classification}

\begin{tabular}{clc}
\hline Label & Sector & ISIC Rev.3 Codes \\
\hline S1 & Food products, beverages and tobacco & $15-16$ \\
S2 & Textiles, textile products, leather and footwear & $17-19$ \\
S3 & Wood, paper, printing, publishing & $20-22$ \\
S4 & Coke, refined petroleum products and nuclear fuel & 23 \\
S5 & Chemicals (including pharmaceuticals) & 24 \\
S6 & Rubber and plastics products & 25 \\
S7 & Other non-metallic mineral products & 26 \\
S8 & Basic metals & 27 \\
S9 & Fabricated metal products (except machinery and equipment) & 28 \\
S10 & Machinery and equipment, nec & 29 \\
S11 & Electrical and optical instruments & $30-33$ \\
S12 & Motor vehicles, trailers and semitrailers & 34 \\
S13 & Other transport equipment & 35 \\
S14 & Manufacturing, nec; recycling & $36-37$ \\
S15 & Electricity, gas and water supply & $40-41$ \\
S16 & Construction & 45 \\
\hline
\end{tabular}

